\title{
ANALYSIS OF THE HUNGARIAN AGRICULTURAL MARKETING - BY THE SUPPLY OF LOCAL PRODUCTS' CONSUMERS
}

\author{
Edina Lendvai, Agnes Ördög \\ University of Szeged, Faculty of Engineering, 6724 Szeged Mars tér 7., Hungary \\ e-mail: lendvai@mk.u-szeged.hu
}

\begin{abstract}
The term agricultural marketing is composed of two words-agriculture and marketing. Agriculture, we can think about the soil, the forests, the sea, so it includes all the primary activities of production systems in relation to animal, plant, food production. But, generally, it is used to mean growing and/or raising crops and livestock. The study of agricultural marketing comprises all the operations, and the agencies conducting them, involved in the movement of farm-produced foods, raw materials and their derivatives, such as textiles, from the farms to the final consumers, and the effects of such operations on farmers, middlemen and consumers.

In our primer research a questionnaire was made by us. The topic of the questionnaire was the consumption of these local products and the knowledge about the common agricultural marketing. The main group of our research was the graduated people, we think, they have more information and income, so they attitude is positive for these products.

We have known, the most of the participants had heard about the agricultural marketing, but the main institute, AMC not yet. The problems with the local products - in the opinion of the participants are: higher price, less choice, no too comfortable shopping.
\end{abstract}

Keywords: agricultural marketing, questionnaire, local products

\section{INTRODUCTION}

Nowadays marketing is the basic for all enterprises, it is important and fundamental activity. We can talk about the industry, the service sector or the agriculture. The income of the company is determined by sales of the produced wealth, their methods and their tools. In our days the marketing management has more effective significance, because of the global market and the vigorous competition.

We can talk about marketing, with the help of AMA (American Marketing Association) it is the activity, set of institutions, and processes for creating, communicating, delivering, and exchanging offerings that have value for customers, clients, partners, and society at large[1]. Kotler's definition: Marketing is the social process by which individuals and organizations obtain what they need and want through creating and exchanging value with others [2].

The majority of people in XIX ${ }^{\text {th }}$ century worked in agriculture, and after the industrial revolution they went to the service sector. About 3-5\% of employee could supply with food the whole society. Moreover the trade stated to be international and global. The choice of goods has become bigger and bigger, the firms have fought with each other, they want to catch the consumers for themselves. The lifetime of the products has done shorter; the communication and the advertising have turned more intensive. Because of the globalism the far countries has get closer to each other, and their consumption and its structure have interlinked [3].

The term agricultural marketing is composed of two words-agriculture and marketing. Agriculture, we can think about the soil, the forests, the sea, so it includes all the primary activities of production systems in relation to animal, plant, food production. But, generally, it is used to mean growing and/or raising crops and livestock. The study of agricultural marketing, comprises all the operations, and the agencies conducting them, involved in the movement of farm-produced foods, raw materials and their derivatives, such as textiles, from the farms to the final consumers, and the effects of such operations on farmers, middlemen and consumers [4].

DOI: 10.14232/analecta.2018.2.37-44 
According to the National Commission on Agriculture [5] agricultural marketing is a process which starts with a conclusion to produce a profitable farm product, and it contains all the aspects of market structure or method, both functional and institutional, based on technical and economic deliberations, and includes preand post-harvest operations.

Meulenberg tried to find the difference between agricultural and simple marketing. He deduced, the agricultural marketing discipline finally will split into agribusiness marketing and agricultural marketing, the prospective lengthening some specific marketing items at the farm level only [6].

The agricultural marketing was developed from the marketing; it covers the raw and the processed food. First it was used in the USA, and people firstly focused to the agricultural products. In the agricultural marketing has spread 4 aspects:

- product (for example meat or milk)

- functional (for example sale)

- organizations (trade units, agents)

- behaviour (between companies and consumers) [7]

Kiruthiga et al have collected the most important things of the agricultural marketing. They has written, that it is very significant, because of the follows [5]:

- Break the vicious circle of poverty

- Optimum utilization of agricultural resources

- Enhance the standard of living

- Basis of employment opportunity

- Basis of industrial development

- Creation of utilization

- Basis of foreign trade

- Source of national revenue

- Create the environment for investment

The FAO study shows the conflict between the agriculture and the industry (table 1). The farmers want the maximum price for their products, but the other participants want low price and maximum quality [8].

Table 1. Conflict of interest in agricultural/food marketing systems

Source: $w w w$.fao.org

\begin{tabular}{|l|l|}
\hline \multicolumn{1}{|c|}{ Key players } & \multicolumn{1}{c|}{ Interest } \\
\hline Farmers & Maximum price, unlimited quantities \\
\hline Manufacturers & Low purchase price, high quality \\
\hline Traders and retailers & Low purchase price, high quality \\
\hline Consumers & Low purchase price, high quality \\
\hline
\end{tabular}


Since 1970's year, because of the degradation of the increase of the food demand and consumption it has become the unilateral competitor orientation. Only the best companies could be survive the war, so the balanced integrative marketing has spread between the marketing managers. It means, that the successfulness of companies has decided by the adaptation to the macro and micro area [9].

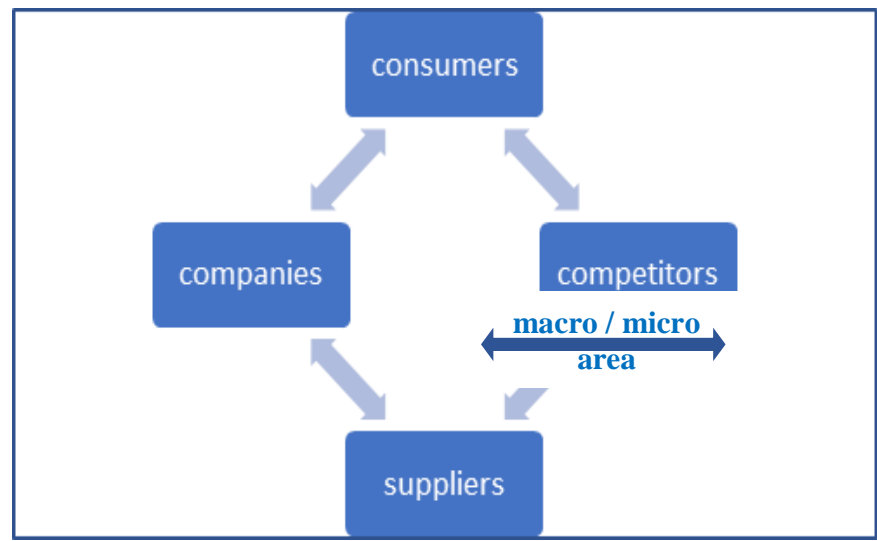

Figure 1. The System of balanced integrative marketing Source [9] (Edited by the authors)

\section{MATERIALS AND METHODS}

In our primer research a questionnaire was made by us. The topic of the questionnaire was the consumption of these local products and the knowledge about the common agricultural marketing. The main group of our research was the graduated people, we think, they have more information and income, so they attitude is positive for these products. The questionnaire was filled by email (in the KSH (Central Statistical office), the employee of KSH must have be graduated, it was upload to the Facebook, between our acquaintances. Finally the questionnaire was answered by 220 persons - from all part of the country.

The first part of the questionnaire is about the knowledge of the agricultural marketing, the AMC (Agricultural Marketing Centre in Hungary) and its activity, after it we asked people about the local products and the consumer's habit. At the end of the survey we can see the demographic questions. The data analysis and diagrams were made by the Microsoft Office Excel 2010 program.

\section{RESULTS AND THEIR EVALUATION}

In the Table 2. we can see the most important data about the answerers. As we have written on the chapter "Means and methods", the selected people were the graduated persons, but of course a few has not got. The distribution of the other criterion is multifarious. 
Table 2. The most important parameters of the answerers $(N=220)$

\begin{tabular}{|c|c|c|}
\hline Parameters & person & $\%$ \\
\hline \multicolumn{3}{|c|}{ Gender } \\
\hline male & 55 & 25 \\
\hline female & 165 & 75 \\
\hline \multicolumn{3}{|c|}{ Age (years) } \\
\hline under 18 & 0 & 0 \\
\hline $18-35$ & 81 & 36,8 \\
\hline $36-55$ & 116 & 52,7 \\
\hline more, than 55 & 23 & 10,5 \\
\hline \multicolumn{3}{|c|}{ Education } \\
\hline basic & 0 & 0 \\
\hline intermediate & 53 & 24,1 \\
\hline graduated & 167 & 75,9 \\
\hline \multicolumn{3}{|c|}{ The type of the living place } \\
\hline Capital & 14 & 6,4 \\
\hline County- centre & 125 & 56,8 \\
\hline city & 51 & 23,2 \\
\hline village & 29 & 13,2 \\
\hline farm & 1 & 0,5 \\
\hline
\end{tabular}

The first question was about the meaning the agricultural marketing. We gave 3 answers, descriptions about it. Most people $(86.8 \%)$ have chosen this sentence: the common agricultural marketing means cooperation, its goal is getting closer the farmers and the consumers, and flowing of the information about the market.

Next multiply choice question is about the known types of agricultural marketing. The answers are on the Figure 2. As we can see most of them have met local market, or any fairs. They visited other events, for example, festivals, or have seen advertisements (Buy Hungarian products - Protect Hungarian products ${ }^{1}$ ). Only 9 people said, they had never met agricultural marketing.

\footnotetext{
${ }^{1}$ In Hungarian language it is a word-joke, too: "Vedd a magyart, védd a magyart!"
} 


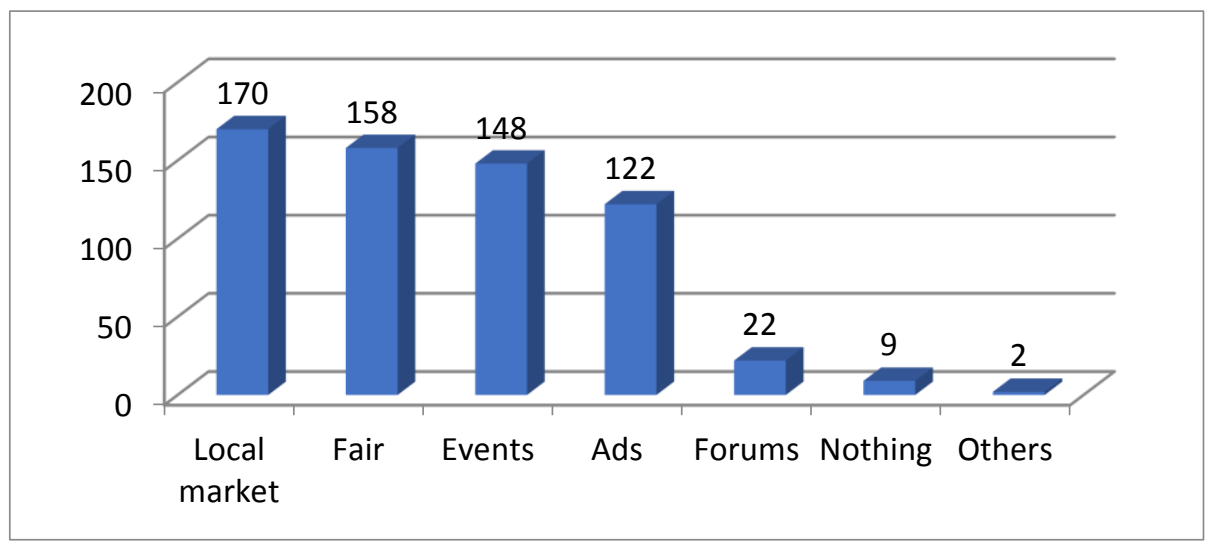

Figure 2. The experiences of the consumers about the agricultural marketing (person, $N=220$ )

In Hungary, the official organization of the agricultural marketing is the Agricultural Marketing Centre $\left(A M C^{2}\right)$. Maybe it is not too surprising, that the overage Hungarian person has never heard the name. In our research the result is same: $60,9 \%$ told this fact. So we hope that our survey will get better known this institute. There are some questions about the most important events of AMC, they are the OMÉK, and the Farmerexpo. The answerers could say their opinion about the happenings, they told, it was "good" (3-93 4-19 average points). They were informed about these programs by the Internet, the friends and the social media. The last question about this topic was the future, if they plan to visit the AMC- events. Most of the people say maybe (53\%), 30\% said yes, and the rest don not want to go to the similar proceedings.

In our next question we ask people about the other programmes were organized not by the AMC. $83.2 \%$ of them went to some events, usually festivals, for example wine, paprika, mangalitza / curly hair hog, Hungarian Great Plain Animal Husbandry and Agricultural Days (in Hódmezővásárhely). We can say these programs are the part of the national agricultural marketing; however it is not organized by the AMC. The importance is enough, because- as we can see - more people know these events, than the mentioned earlier. Answerers were informed by similar method, like the AMC programs: internet, social media, advertisements, and friends.

More, than half of our group plans to go back to the happenings, festivals, only $2 \%$ said, that it is probably not.

After the questions of agricultural marketing and AMC, we turned to the buying habits about local products. $86.8 \%$ of 220 survey respondents said yes, they have ever bought a local product. It means our sample-number has changed to 189 . Most of them purchased food (40\%), home-made goods /artisanal products are on the $2^{\text {nd }}$ place $(22 \%)$ and those follows the processed food $(16 \%)$. Some people marked the alcohol and the cosmetics, but it seems, the food products, especially raw foods are the winner (figure 3 ).

\footnotetext{
${ }^{2}$ Agrármarketing Centrum
} 


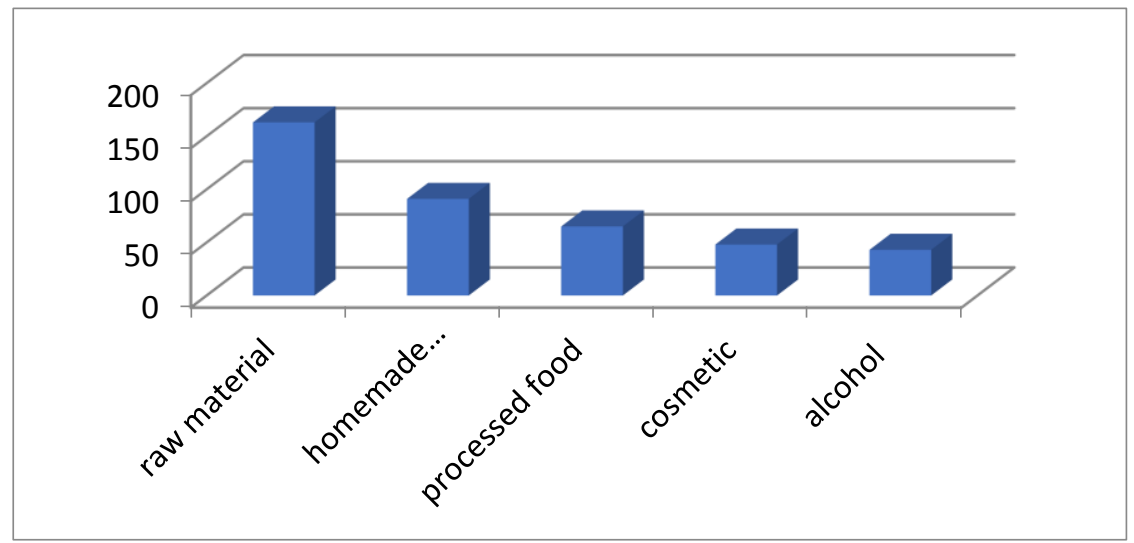

Figure 3. Distribution of the types of the products-purchased by the responders. $(N=189)$

We try to know, what the most important motivations of the shopping are. We gave 9 aspects, they are:

- it is made from local raw

- quality

- less price

- healthy lifestyle

- bioproducts

- knowing the farmer / producer

- sustainability

- direct connection with the farmer / producer

- strengthen local economy

Everybody could give point (from 1 to 5 ) to indicate their opinion. Table 3 summarizes the results. We clearly can see, the quality is the most important motivation, because our respondents gave the highest points for this possibility. It means, they can believe in these products. There are two motivations upper than 4 points, the using of local raw material and the healthy lifestyle. Less important role is the bioproducts, the farmer- knowing, the less-price and the sustainability. 
Table 3. The average points of the reason, because somebody buy local product $(N=189)$

\begin{tabular}{|l|r|}
\hline \multicolumn{1}{|c|}{ Aspect } & average point \\
\hline it is made from local raw & 4,13 \\
\hline quality & 4,58 \\
\hline less price & 3,55 \\
\hline healthy lifestyle & 4,10 \\
\hline bioproducts & 2,71 \\
\hline knowing the farmer / producer & 3,41 \\
\hline sustainability & 3,55 \\
\hline $\begin{array}{l}\text { direct connection with the farmer / } \\
\text { producer }\end{array}$ & 3,51 \\
\hline strengthen local economy & 3,97 \\
\hline
\end{tabular}

After the motivation we asked people, tell us about their disappointment, connected with local products. 82 $\%$ of them have never felt it, it is a good result. The rest people mentioned the not too god quality and the high price of the product. But, some of them noticed, they had bought the product from the trader and not the producer / farmer. There is a little contradiction, because in the motivation the fewer prices appear at the end, but now persons noticed higher price.

In the last question, when we ask everybody, we want to know the opinion of the answerers, are there any problems associated to the purchasing local products. We gave some key factors:

- food quality risk,

- higher price,

- less choice,

- no too comfortable shopping,

- extensive duration for purchasing,

- seasonality,

and of course was the "other" and the "no problems" possibility too. The results we can see on Figure 4.

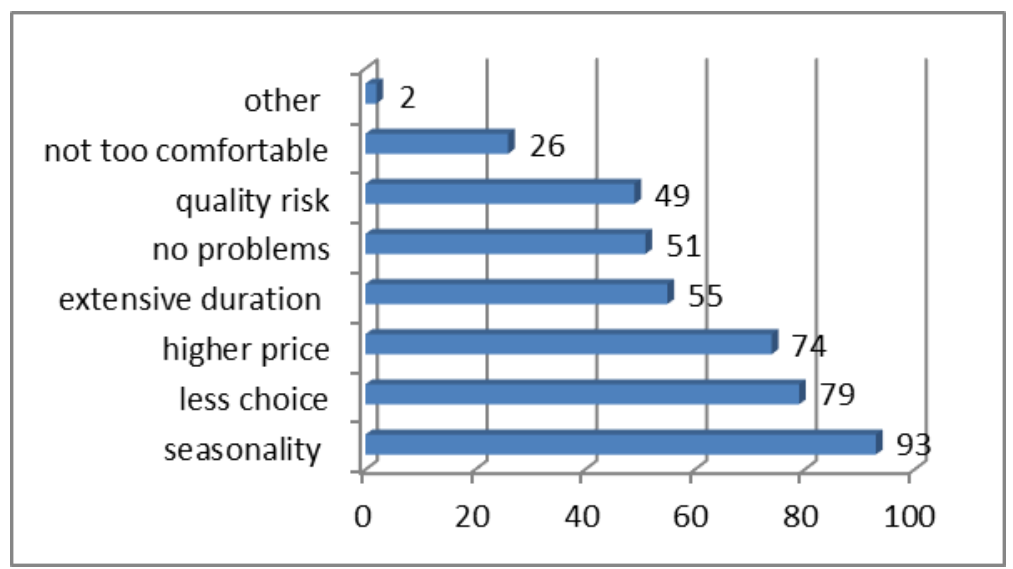

Figure 4. The distribution of the problems - by the survey participants. (Person, $N=220$ ) 
Most of them perceived the seasonality and - because of it - the less choice. Really, in supermarkets we can buy always everything. They mentioned the higher price (because of the individuality and more handwork), extensive duration of the shopping (we cannot buy in the same place), and, sometimes the quality risk. Our opinion, it is happens products in the field industrial, too. About $25 \%$ didn't sense any problems.

\section{CONCLUSION}

In our survey we tried to know the opinion and cognition about the agricultural marketing, the Agricultural Marketing Centre and local products. To achieve our goal we made a questionnaire. It was filed by 220 persons. They are - usually - graduated persons; mainly we wanted to reach them.

We have known, the most of the participants had heard about the agricultural marketing, but the main institute, AMC not yet. The AMC programs are not too famous by them, but the other, similar festivals are prominent. We think the reason is the place of the events, the AMC sponsored happenings are in Budapest, the others are in big cities all over the country.

The big part of our survey-responsible have bought local product, because of the quality and the local raw material and healthy lifestyle. Fortunately, they are satisfied with these products, the main problem is the seasonality and the less choice.

Our suggestions are:

- It should be good to organize by AMC minors programmes in the county seats, or big cities

- For the aware consumption at the school, for students have to give talks about the local economy

- Local farmers /producers should be invite children / families, to know their process and products.

\section{REFERENCES:}

[1] https://www.ama.org/AboutAMA/Pages/Definition-of-Marketing.aspx

[2] Philip Kotler - Gary Armstrong (2010): Principles of marketing Pearson Prentice Hall

[3] Bauer András - Berács József (2001): marketing. Akadémiai Kiadó

[4] Frederic Lundy Thomsem (1951): Agricultural marketing McGraw-Hill

[5] K.Kiruthiga, R.Karthi, B.Asha Daisy (2015): Agricultural Marketing - An Overview International Journal of Scientific and Research Publications, Volume 5, Issue 4, April 2015

[6] Meulenberg, Mathew T G (1986): The evolution of agricultural marketing theory: towards better coordination with general marketing theory. Netherlands Journal of Agricultural Science 34 (1986) 301-315

[7] Lehota József - Tomcsányi (1994): Agrármarketing. Mezőgazda Kiadó

[8] http://www.fao.org/docrep/004/w3240e/W3240E01.htm

[9] Szakály et al (2010): Marketing a hagyományos és tájjellegû élelmiszerek piacán Kaposvár 